Research Article

\title{
Finite Element Analysis of Vertical and Horizontal Drainage Structures under Vacuum Combined Surcharge Preloading
}

\author{
Daqing Wang, ${ }^{1}$ Dong Wei, ${ }^{1}$ Guoyi Lin, ${ }^{1}$ Jiannan Zheng, ${ }^{1}$ Zhiting Tang, ${ }^{1}$ Litao Fan $\left(\mathbb{D},{ }^{2}\right.$ \\ and Bingxiang Yuan $\mathbb{1}^{2}$ \\ ${ }^{1}$ China Construction Fourth Engineering Bureau Limited, Guangzhou 510280, China \\ ${ }^{2}$ School of Civil and Transportation Engineering, Guangdong University of Technology, Guangzhou 510006, China \\ Correspondence should be addressed to Bingxiang Yuan; yuanbx@gdut.edu.cn
}

Received 28 October 2021; Accepted 13 November 2021; Published 27 November 2021

Academic Editor: Yu Liang

Copyright (C) 2021 Daqing Wang et al. This is an open access article distributed under the Creative Commons Attribution License, which permits unrestricted use, distribution, and reproduction in any medium, provided the original work is properly cited.

Combined vacuum and surcharge preloading has gradually been widely used because of its advantages of low cost, green environmental protection, and good treatment effect. The conventional prefabricated vertical drain presents obvious defects in vacuum preloading treatment, such as obvious silting, serious bending of the drainage board, large attenuation of vacuum degree of drainage board along the depth, long construction period, and so on, which affect the final reinforcement effect. In this paper, the MIDAS finite element simulation of combined vacuum and surcharge preloading of prefabricated vertical drains (PVDs) and prefabricated horizontal drains (PHDs) is established through the comparative experiment of the engineering field. The comparative experimental study is carried out from the aspects of the vertical settlement, horizontal displacement, and pore water pressure. The results show that under combined vacuum and surcharge preloading, the consolidation effect of soft soil with PHDs is better than that with PVDs. When PHDs are used, the vertical settlement increases by $7.2 \%$ compared with PVDs; the horizontal displacement is larger; and the pore water pressure dissipates faster. This is because when the PHDs are adopted, the consolidation direction of the soil is consistent with the direction of the vacuum suction, which is mainly caused by vertical settlement. With the consolidation, the spacing between PHDs is gradually shortened, and the drainage distance is reduced, which can effectively reduce the consolidation time and improve the reinforcement effect of the soil. In addition, the PHDs can move downward uniformly with the soil during the consolidation process and have almost no bending deformation, which makes the vacuum transfer more uniform and effective.

\section{Introduction}

The vacuum-surcharge preloading method is an economic and effective soft foundation treatment method, which has been widely used in large-area soft foundation treatment, and its advantages in foundation treatment are very obvious. As early as the 1980s, a large number of scholars in China have been exploring the application of vacuum combined surcharge preloading method to practical engineering. Through exploring and testing to solve the key problems in the process, the Scientific Research Institute of the First Aviation Administration has achieved success in the field test of large-area vacuum combined surcharge [1]. Shang [2] obtained the best consolidation effect and economic benefit of combined vacuum and surcharge preloading through field comparative tests. Subsequently, due to the update of theory [3-6] and the progress of construction technology, with the further development of indoor model test and finite element numerical simulation [7-9], the vacuum-surcharge preloading method is widely applied to practical engineering. Through engineering example and stress route analysis, Lou and Yi [10] put forward the necessity of graded loading for soft foundation strengthened by vacuum combined surcharge preloading. Yuan and $\mathrm{Lu}[11,12]$ studied the deformation characteristics of micro prefabricated vertical drainage unit by changing the loading rate of heaped pressure and vacuum pressure so that the soft soil was consolidated more fully and the consolidation efficiency was 
improved. Jin et al. [13] used vacuum combined surcharge preloading method to reinforce soft foundation with confined water and introduced the construction technology to prevent the penetration of confined water. Based on the combined surcharge preloading model test, the lateral pressure is applied to the internal air injection of the filled foundation, which has a significant effect on improving the consolidation degree of the soil $[14,15]$.

However, the engineering practice shows that the vacuum preloading method using PVDs has the following problems: the drainage plate is easy to silt up, and the soil column is formed around the drainage plate, leading to uneven settlement $[16,17]$. The attenuation of vacuum along the PVDs leads to the poor treatment effect of deep soil [18-20] and a long construction period [21, 22]. This is mainly due to the fact that in the process of vacuum preloading, small particles are easily blocked in the filter membrane pores of the drainage plate, resulting in siltation of the drainage plate. Subsequently, fine particles continue to migrate to the drainage plate and accumulate near the drainage plate, forming soil columns with extremely poor permeability around the drainage plate, which greatly reduces the drainage rate and seriously affects the efficiency of drainage consolidation.

Therefore, the research on prefabricated horizontal drains (PHDs) is gradually carried out. In the early stage, Lee [23] used horizontal shallow sand-clay layer instead of vertical sand wells as drainage body to reinforce dredger fill silt and proved its feasibility. Jin et al. [24] used the laboratory test results of the middle well and soil box test to simulate the local installation of horizontal drainage pipe and discussed the estimation of the best negative pressure. $\mathrm{Li}$ [25] successfully completed vacuum dehydration using a horizontal geosynthetic drainage blanket, and the placement of a horizontal geosynthetic drainage blanket also enhanced the strength and stability of silt. In the domestic research, Bao et al. [26] research showed that horizontal integral drainage plate is more conducive to the transmission of vacuum in soil. By comparing the vacuum preloading effect of the vertical drainage plate and horizontal drainage plate, it is concluded that the physical and mechanical indexes of PHDs are better than those of PVDs, and the deformation of PHDs is smaller than that of PVDs $[27,28]$. In addition, the PHD has a better reinforcement effect on dredged silt because its vertical spacing decreases with settlement, and drainage path is shorter $[29,30]$. Wang et al. [31] proposed a method about combining vacuum preloading with electroosmosis using prefabricated horizontal drain (EPHD) to treat dredged fill sludge and compared it with combining vacuum preloading with electroosmosis using prefabricated vertical drain (EPVD). EPHD showed obvious advantages in drainage efficiency, reinforcement efficiency, and economy.

Based on the above analysis, PHDs + vacuum preloading method as a promising dredging sludge treatment method can effectively solve the traditional vacuum preloading consolidation stress limitation, vacuum attenuation along the depth, the reinforcement effect of deep soil that is not ideal, uneven settlement, and other shortcomings. In order to further explore the mechanism and effect of PHDs in soft foundation reinforcement, this paper simulates the actual project of vacuum combined surcharge preloading by MIDAS.GTS.NX finite element software. By comprehensively comparing the effects of PHDs and PVDs on the reinforcement effect of soft foundation, the advantages of PHDs + vacuum combined surcharge preloading method are discussed.

\section{Project Profile}

The first-stage project from Xinhuicheng to Yamen section of Guangfo River Expressway is located in the central and western part of Guangdong Province, China. The total area of foundation treatment is divided into 13 treatment areas, as shown in Figure 1, and the foundation treatment methods in areas 1, 3, and 6-10 are plastic drainage plate + vacuum combined surcharge preloading method. In this paper, area 1 is selected as the research object for simulation analysis. The soft foundation treatment area is $48 \mathrm{~m} \times 106.9 \mathrm{~m}$, and some of them are used as field experiments in this study. The silt soft soil in the region has the characteristics of "three high and one low," that is, high water content, high porosity ratio, high sensitivity, and low strength. Engineering properties are poor, so soft foundation treatment is needed to be developed and utilized. The basic physical and mechanical properties of the soil layer in the region are shown in Table 1.

According to the requirements of the construction design drawings, the first step is the preliminary preparation, such as leveling the site and digging the drainage ditch. Then lay the lower sand cushion, and then carry out the construction of plastic drainage board. The foundation treatment depth is about $13 \mathrm{~m}$, and the buried depth of the plastic drainage plate is $12 \mathrm{~m}$. The PVDs and PHDs are buried, respectively. After the plastic drainage board is completed, the upper sand cushion is laid, and vacuum preloading is started. The vacuum pressure under the membrane can be maintained at $85 \mathrm{kPa}$ after 10 days of the vacuum pumping. When the reinforcement effect of vacuum preloading method was gradually weakened in the later stage, the stack preloading was carried out, and the accumulated loading was three levels. The vacuum preloading can be stopped after the settlement meets the design requirements by analyzing the settlement observation data. The vacuum pumping time of the whole test process is about 3 months.

\subsection{Experimental Method and Finite Element Establishment}

2.1.1. Theoretical Analysis of Consolidation. When Terzaghi studied the consolidation characteristics of soil in 1925, he proposed and established a one-dimensional consolidation differential equation, which laid the theoretical foundation of consolidation in classical soil mechanics. On this basis, Biot proposed the three-dimensional consolidation theory of soil in 1943. The consolidation problem of soil can be understood as the transformation process of effective stress in soil. Through the coupling effect of continuous conditions and compression conditions of the interaction between laminar pore water and 


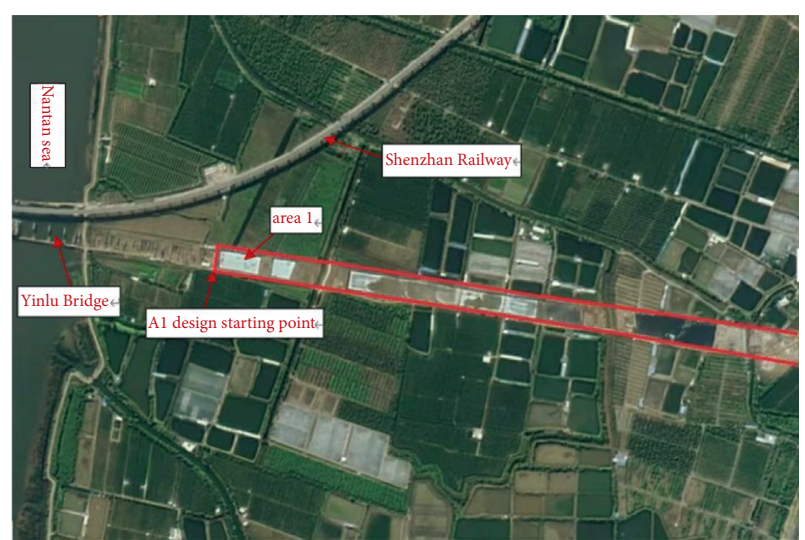

Figure 1: Aerial view of engineering site.

soil skeleton, the physical equation, geometric equation, and continuity equation of soil are constructed. The consolidation equation is solved by Darcy's law and boundary conditions.

In vacuum combined surcharge preloading, due to the existence of drainage plate, the drainage consolidation problem of foundation reinforced by vacuum combined surcharge preloading method is a three-dimensional problem. However, due to the dense drainage plate arranged in a soft soil foundation, it can be assumed that the drainage plate is connected into a plane in the longitudinal direction, and then it is simplified into a plane strain problem for processing. Therefore, Biot's consolidation equation can be simplified as follows:

$$
\left\{\begin{array}{l}
-G \nabla^{2} w_{x}-\frac{G}{1-2 \nu} g \frac{\partial \varepsilon_{v}}{\partial x}+\frac{\partial u}{\partial x}=0 \\
-G \nabla^{2} w_{z}-\frac{G}{1-2 \nu} g \frac{\partial \varepsilon_{v}}{\partial z}+\frac{\partial u}{\partial z}=-\gamma \\
\frac{\partial \varepsilon_{v}}{\partial t}+\frac{K}{\gamma_{w}} \nabla^{2} u=0
\end{array}\right.
$$

where $G$ is the soil shear modulus; $v$ is Poisson's ratio; $u$ is pore water pressure; $K$ is the permeability coefficient, assuming that the permeability coefficient in the soil is the same in all directions; and $\gamma_{\mathrm{w}}$ and $\gamma$ are the gravity of water and the gravity of soil, respectively. Under the plane strain condition, the Laplace operator and volumetric strain in the equation are expressed as follows:

$$
\begin{aligned}
\nabla^{2} & =\frac{\partial}{\partial x^{2}}+\frac{\partial}{\partial z^{2}} \\
\varepsilon_{v} & =-\left(\frac{\partial w_{x}}{\partial x}+\frac{\partial w_{z}}{\partial z}\right) .
\end{aligned}
$$

2.1.2. Equivalent Principle of Drainage Plate. Using vacuum combined surcharge preloading method to reinforce soft soil foundation, drainage plate should be inserted into the foundation. The function of the drainage plate is to drain and transfer vacuum negative pressure. The plastic drainage plate cannot be simulated in the plane calculation model of finite element, so the drainage plate is converted into the sand wall for processing. Firstly, the drainage plate is equivalent to sand well. The basic idea is to make the cylindrical sand well; the plastic drainage plate has the same drainage capacity; and the diameter of the sand well can be set as the equivalent diameter of the drainage plate. Hansbo (1979) first proposed that the equivalent diameter formula of plastic drainage plate can be expressed as [32]:

$$
d_{w}=\alpha \frac{2(a+b)}{\pi}
$$

where $d_{\mathrm{w}}$ is the equivalent diameter of the drainage plate; $a$ and $b$ are the width value and thickness value of plastic drainage plate, respectively; and $\alpha$ is the conversion coefficient, usually $0.75 \sim 1.0$.

The consolidation problem of sand wells should be calculated by a three-dimensional spatial model. However, due to the heavy workload of three-dimensional finite element analysis itself, coupled with dense sand wells, the mesh elements are greatly increased. The calculation can be greatly reduced by using two-dimensional plane finite element analysis. Therefore, on the basis of transforming plastic drainage plate into the sand well, the sand well is transformed into the sand wall, and the space problem is transformed into the plane problem to simplify the calculation. The relationship between permeability coefficient of converted sand wall and permeability coefficient of sand well is as follows [33]:

$$
\begin{aligned}
& k_{x p}=D_{x} k_{x a}, \\
& k_{z p}=D_{z} k_{z a},
\end{aligned}
$$

where $k_{\mathrm{xa}}$ and $k_{\mathrm{za}}$ are the horizontal and vertical actual permeability coefficient of sand well foundation, respectively, and $D_{\mathrm{x}}$ and $D_{\mathrm{z}}$ are horizontal and vertical permeability coefficient adjustment coefficient, respectively; the calculation formula are as follows:

$$
\begin{aligned}
& D_{x}=\frac{4(\eta p-s p)^{2}(1+v) L^{2}}{9 \eta_{p}^{2} \mu_{a}-12 \beta\left(n_{p}-s_{p}\right)\left(s_{p}-1\right)(1+v) L^{2}}, \\
& D_{z}=\frac{2(1+v)}{3},
\end{aligned}
$$

where

$\mu_{a}=n^{2} / n^{2}-s^{2} \ln n / s-\left(3 n^{2}-s^{2}\right) / 4 n^{2}+k_{r a} / k_{s}\left(n^{2}-s^{2}\right) / n^{2}$ In $s ; L=B / r_{\mathrm{e}}$ is the magnification of sand well spacing; $B$ and $r_{\mathrm{e}}$ are half of sand wall spacing and effective drainage radius, respectively; $\beta$ is the ratio of horizontal actual permeability coefficient $\left(k_{\mathrm{xa}}\right)$ to permeability coefficient of smearing area $\left(k_{\mathrm{sp}}\right) ; n_{\mathrm{p}}$ is the ratio of half of sand wall spacing $(B)$ to sand well radius $\left(r_{\mathrm{wp}}\right) ; s_{\mathrm{p}}$ is the ratio of the distance from the center of sand well to the outer edge of smearing area $\left(r_{\mathrm{sp}}\right)$ to half of the thickness of the sand wall $\left(r_{\mathrm{wp}}\right) ; n=r_{\mathrm{e}} / r_{\mathrm{wa}}$ is hole diameter ratio; $r_{\mathrm{wa}}$ is the radius of sand well; $s=r_{\mathrm{s}} / r_{\mathrm{wa}}$ is coating ratio; $r_{\mathrm{s}}$ is the smear radius; and $v$ is Poisson's ratio of soil. 
TABLE 1: Basic physical parameters of the soil layer.

\begin{tabular}{|c|c|c|c|c|c|}
\hline Parameter & Sand cushion & Plain fill & Silt & Mucky soil & Silty clay \\
\hline Depth (m) & 1.0 & 1.0 & 8.0 & 4.0 & 6.0 \\
\hline$\Gamma\left(\mathrm{kN} / \mathrm{m}^{3}\right)$ & 18.7 & 17.0 & 16.6 & 18.4 & 20 \\
\hline$v$ & 0.25 & 0.35 & 0.38 & 0.37 & 0.37 \\
\hline$e_{0}$ & 0.6 & 0.65 & 1.6 & 1.2 & 0.7 \\
\hline$E(\mathrm{kPa})$ & 12,000 & 3,590 & 2,380 & 2,650 & 4,270 \\
\hline $\mathrm{C}(\mathrm{kPa})$ & 1 & 12 & 8 & 10 & 15 \\
\hline$\Phi\left(^{\circ}\right)$ & 20 & 15 & 4 & 12 & 17 \\
\hline$K(\mathrm{~m} / \mathrm{s})$ & $1.35 \times 10^{-3}$ & $3.75 \times 10^{-5}$ & $1.55 \times 10^{-9}$ & $6.26 \times 10^{-8}$ & $1.55 \times 10^{-6}$ \\
\hline
\end{tabular}

Note: $\gamma$ is the weight of the soil; $v$ is Poisson ratio; $e_{0}$ and $E$ are initial void ratio and elastic modulus, respectively; $C$ and $\Phi$ are the cohesion and internal friction angle of soil, respectively; and $k$ denotes the permeability coefficient.

2.1.3. Establishment of MIDAS Finite Element. The consolidation problem of vacuum combined surcharge preloading is actually a three-dimensional consolidation problem. However, due to the existence of plastic drainage plates, the calculation cost of three-dimensional finite element analysis is too high. In addition, many scholars can get better results through the calculation of a two-dimensional finite element model. Therefore, this paper selects MIDAS.GTS.NX finite element numerical software to carry out two-dimensional plane strain finite element analysis of vacuum combined surcharge preloading. In this paper, the local area of 1 area is selected for finite element analysis. The reinforcement width of the model is $20 \mathrm{~m}$, and the vacuum preloading can affect the soil below the bottom of the drainage plate and outside the reinforcement area. Therefore, the width and height of the calculation model are $80 \mathrm{~mm}$ and $20 \mathrm{~m}$. The drainage plate size is $4.5 \mathrm{~mm} \times 100 \mathrm{~mm}$, and the embedded depth is $12 \mathrm{~m}$. For the vertical drainage system, the spacing of the PVDs is $1 \mathrm{~m}$. In order to ensure that the length of PHDs and PVDs in the experimental area is consistent, the spacing of the adjacent PHD in the horizontal drainage system is $1.2 \mathrm{~m}$. The equivalent diameter and permeability coefficient of the plastic drainage plate can be calculated according to formulas (2)-6 The parameters of the drainage plate are shown in Table 2.

According to the basic parameters of the soil layer and the drain plate, the model and grid division can be obtained, as shown in Figure 2. The numerical simulation analysis of vacuum combined surcharge preloading with PVDs and PHDs is carried out, respectively. The load in the vacuum combined surcharge preloading is mainly the self-weight of the soil, the vacuum negative pressure in the drainage body, and the surcharge pressure acting on the surface of the soil in the reinforcement area. Therefore, the construction simulation mainly has the following three stages:

(1) Initial stress stage: activate all soil layers (including sand cushions), drainage plate, foundation boundary constraints, and weight. In the definition construction, check the displacement to zero and set the displacement in the initial stress stage to the initial value.

(2) Vacuum preloading stage: activate cushion drainage conditions and drainage plate drainage conditions. The vacuum load is set to negative node pressure head, duration of 30 days.
(3) Vacuum combined surcharge stage: activate the surcharge soil and its nonconsolidation conditions and carry out graded surcharge. After each stage of surcharge, it will stand for 10 days. After the end of the last stage of surcharge, it will stand until the consolidation effect is obviously weak.

\section{Results and Analysis}

3.1. Calculation and Analysis of Vertical Settlement Displacement. Figure 3 is the final settlement calculation cloud chart of vacuum combined surcharge preloading with two different drainage plates. It can be seen from the figure that whether PVDs or PHDs are used, the settlement deformation of the soil layer from top to bottom is concave. With the increase of depth, the settlement of soil is decreasing, and the settlement tends to be gentle. The settlement contour of soil at the bottom of the drainage plate is similar to a straight line. The settlement mainly occurs in the range of the reinforcement area, and there is a certain degree of influence outside the influence area. This is mainly because the soil in the reinforcement area moves to the influence area under the action of vacuum combined surcharge. Figure 4 shows the relationship between the depth at the center of the reinforcement area and the final settlement. It can be obtained that the soil settlement on the surface is the largest, and the maximum settlement of the soil in PVDs is smaller than that in PHDs. The maximum settlement of the two drainboards is $0.692 \mathrm{~m}$ and $0.742 \mathrm{~m}$, respectively. This is because when the PHDs are used, the consolidation direction of the soil is consistent with the direction of the vacuum suction, that is, the vertical settlement is mainly caused. With the progress of consolidation, the distance between adjacent PHD is gradually shortened, and the drainage distance is reduced, which can effectively reduce the consolidation time and improve the soil reinforcement effect.

The surface central point of the preloading area is analyzed to obtain the surface subsidence-time curve of the central point (Figure 5). As shown in the figure, the two drainage modes have rapid settlement under the action of vacuum preloading, accounting for about $60 \%$ of the total settlement. In the early stage of vacuum preloading, the surface settlement changes almost linearly, while the later stage of the preloading gradually slows down. At the 
TABLE 2: Equivalent parameters of drainage plates.

\begin{tabular}{lccccccccc}
\hline Parameters & $E(\mathrm{kPa})$ & $S(\mathrm{~m})$ & $v$ & $d_{w}(\mathrm{~m})$ & $K(\mathrm{~m} / \mathrm{s})$ & $D_{x}$ & $D_{z}$ & $k_{x}(\mathrm{~m} / \mathrm{s})$ & $k_{z}(\mathrm{~m} / \mathrm{s})$ \\
\hline Value & 6,000 & 1.0 & 0.25 & 0.06 & $5.8 \times 10^{-6}$ & 1.05 & 0.83 & $6.1 \times 10^{-6}$ & $4.8 \times 10^{-6}$ \\
\hline
\end{tabular}

Note. $E$ is elastic modulus; $s$ and $v$ are the spacing and Poisson's ratio of drainage plates, respectively; $d_{\mathrm{w}}$ is the equivalent radius; $k$ denotes the original permeability coefficient; $D_{\mathrm{x}}$ and $D_{\mathrm{z}}$ are the adjustment coefficients of horizontal and vertical permeability coefficients, respectively; and $k_{\mathrm{x}}$ and $k_{\mathrm{z}}$ are the adjusted horizontal and vertical permeability coefficients, respectively.

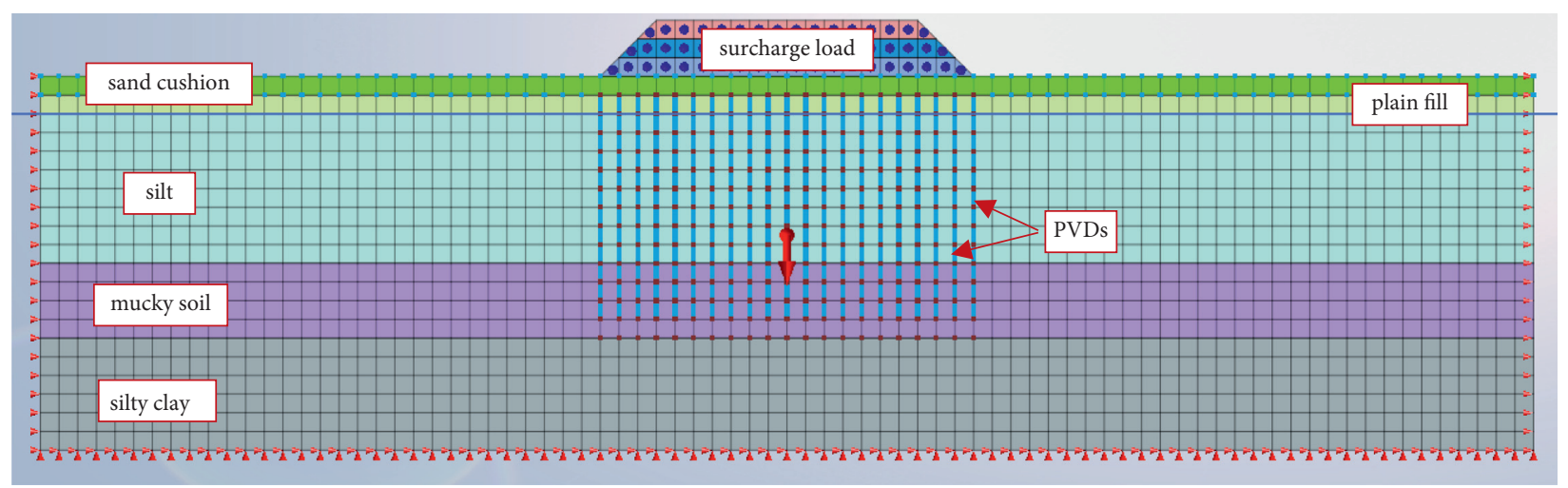

(a)

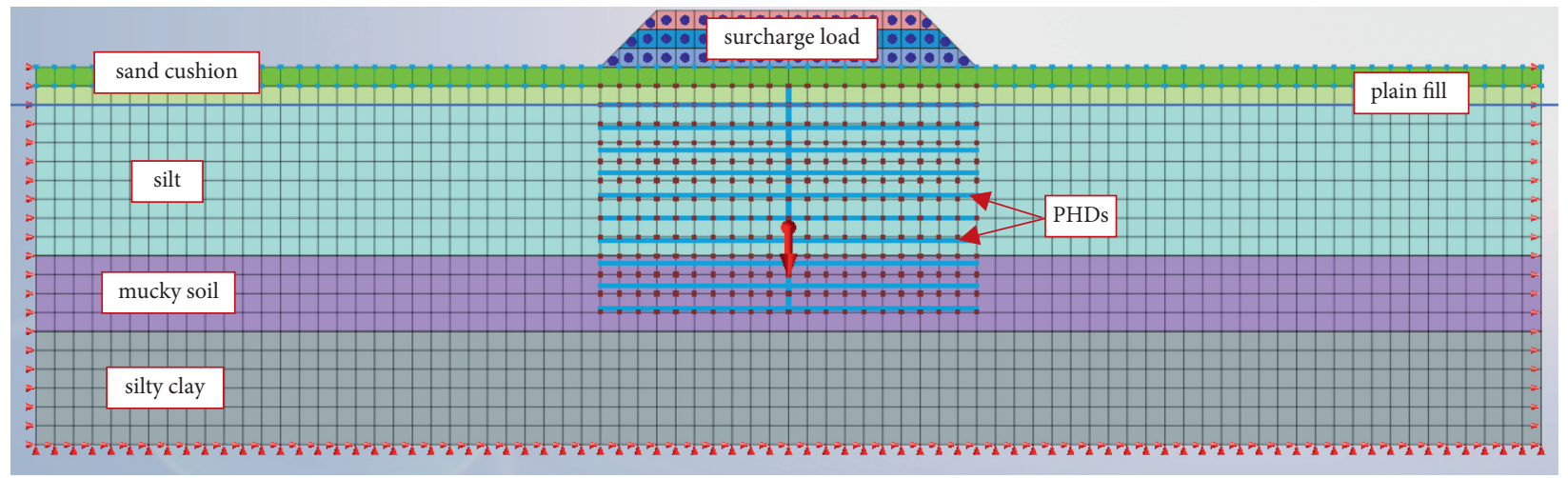

(b)

FIGURE 2: Finite element model of vacuum combined surcharge preloading: (a) PVDs and (b) PHDs.

beginning of preloading, the settlement increases significantly and then gradually slows down. The settlement in the last 30 days accounts for only $3 \%$ of the total settlement. This is because when the loading starts, the discharge rate of excess pore water is fast, the pore water pressure is converted into effective stress, and the pores in the soil are reduced. In the later stage, fine particles are easy to block the filter membrane of the drainage plate and continue to gather, forming a "soil column" near the drainage plate, resulting in the decline of drainage efficiency and slow settlement in the later stage.

In general, the surface settlement with the PHDs is larger than that with the PVDs. This is because in the process of consolidation with PVDs, due to the initial stress of the soil and the compression and bending of the plate, the drainage plate has serious deformation and obvious bending to one side. The distance between PVDs is getting farther and farther, and the drainage path is lengthened, so the consolidation drainage is more difficult. In the consolidation process with PHDs, the drainage plate can move down uniformly with the soil, and the plate has almost no bending deformation, which makes the vacuum transfer more uniform and effective. Figure 6 shows the displacement vector diagrams of the two drainage plates. Figure 6 shows the displacement vector diagrams of two kinds of drainage plates. It can be seen from the figure that the deformation of the drainage plate gradually decreases with the increase of depth. The drain plate with the largest displacement for analysis is taken, and the results shown in Figure 7 are obtained. The maximum displacement difference of the PHDs is $50 \mathrm{~mm}$, and the maximum displacement difference of the PVDs is $80 \mathrm{~mm}$, that is, the deformation of the horizontal drainage plate is smaller than the vertical drainage plate.

\subsection{Calculation and Analysis of Horizontal Displacement.} Figure 8 is the horizontal displacement cloud chart of vacuum combined surcharge preloading using two kinds of 


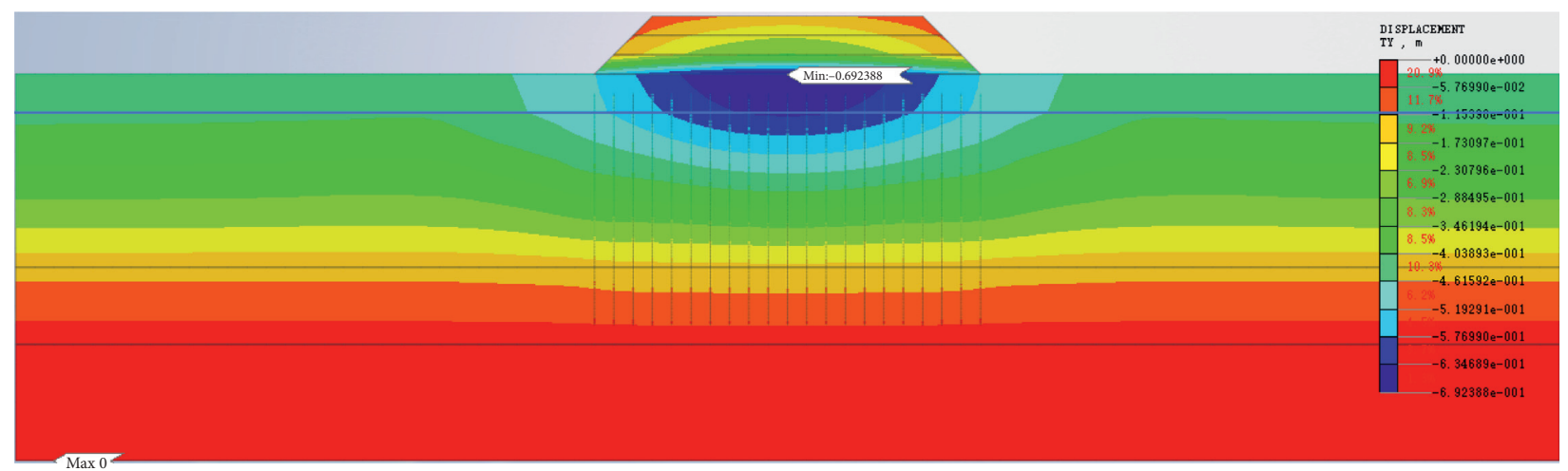

(a)

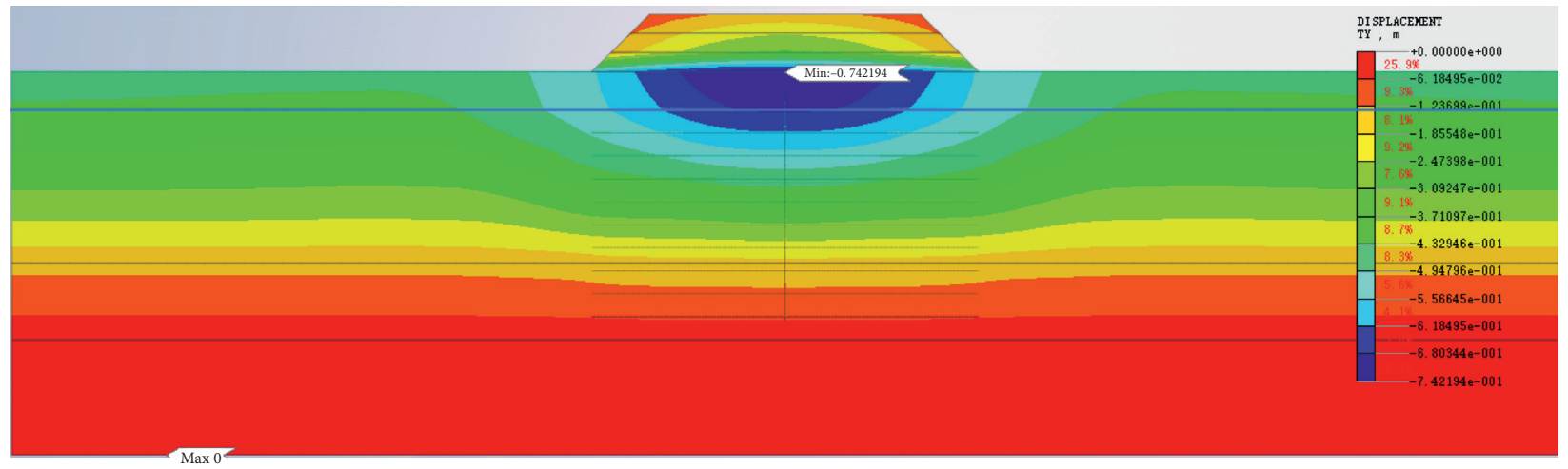

(b)

FIGURE 3: Vertical settlement nephogram of finite element: (a) vertical drainage and (b) horizontal drainage.

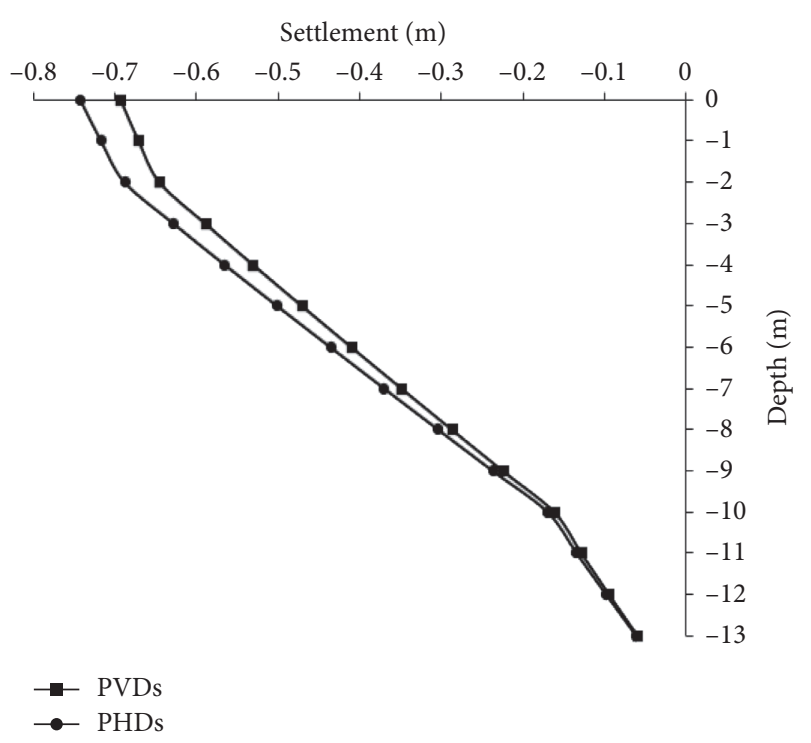

FIGURE 4: Relationship curve between depth and final settlement.

drainage plates. It can be seen from the figure that the maximum positive and negative horizontal displacement occurs between the first and second layers of the soil during the vacuum combined surcharge preloading, and the influence range of the influence area is larger than that of the settlement area. The maximum horizontal displacement of

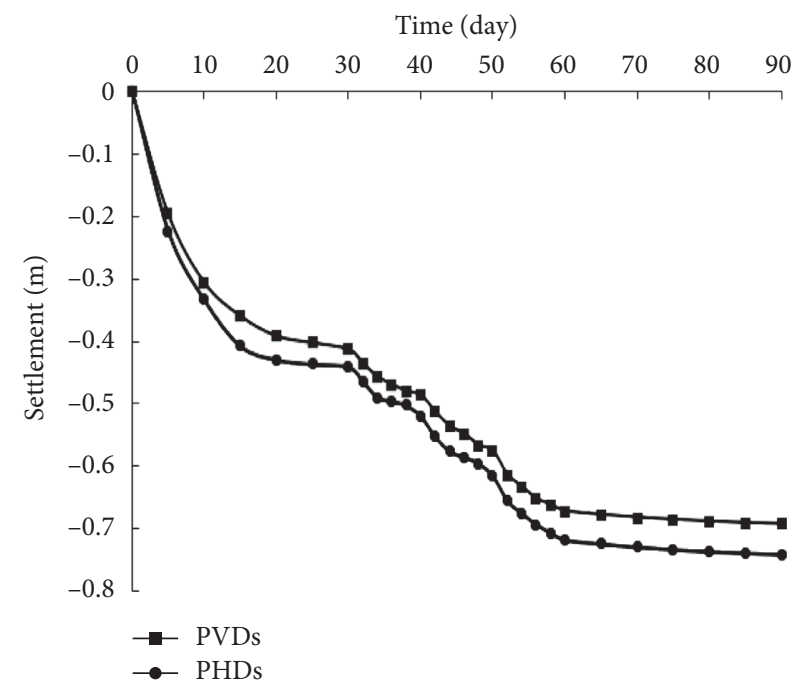

FIgURE 5: Central subsidence of surface and its relation curve.

the vacuum combined surcharge preloading with PHDs is larger than that with PVDs, which are $96.8 \mathrm{~mm}$ and $93.8 \mathrm{~mm}$, respectively, and the difference is $3 \mathrm{~mm}$. When the buried depth is $6 \mathrm{~m}$, the horizontal displacement of the soil at the junction of the affected area and the reinforcement area is analyzed, as shown in Figure 9. In the process of vacuum loading, the soil in the affected area is 


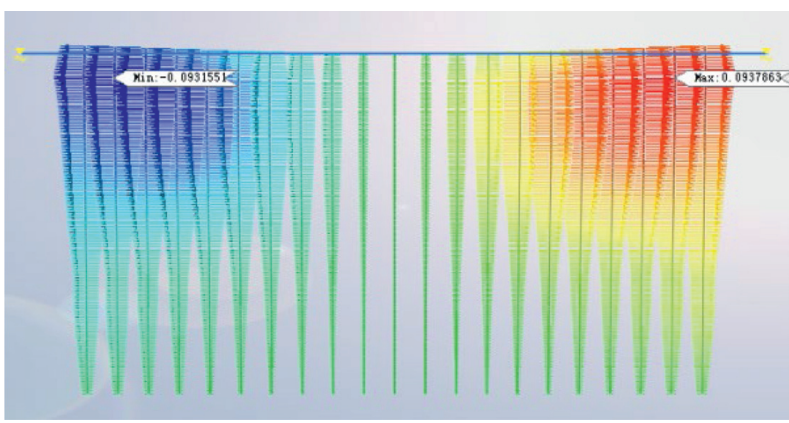

(a)

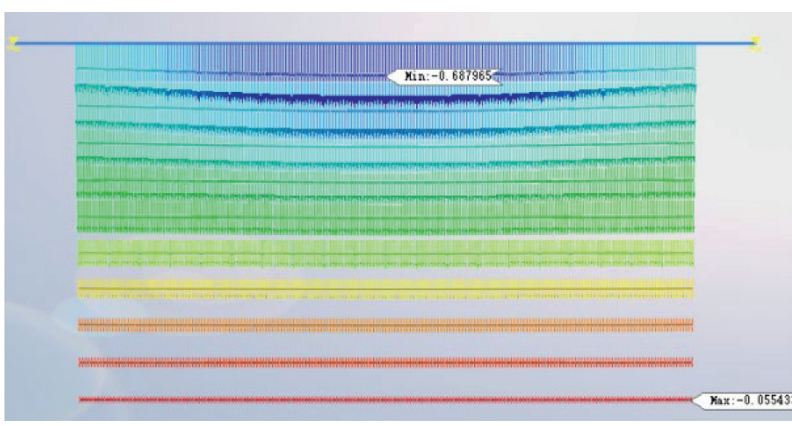

(b)

FIgURE 6: Displacement vector diagram of drainage plate: (a) PVDs and (b) PHDs.

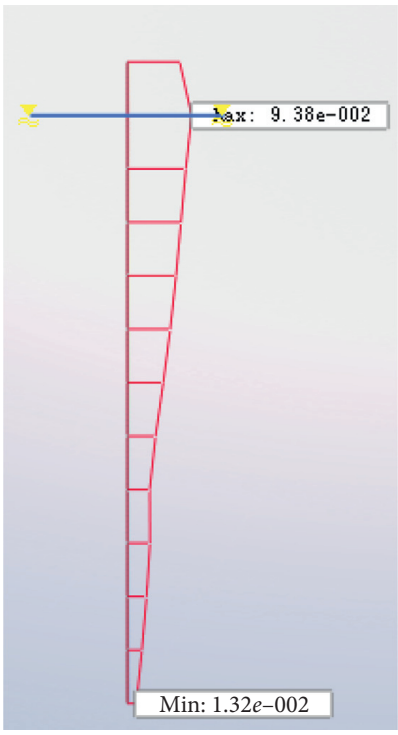

(a)

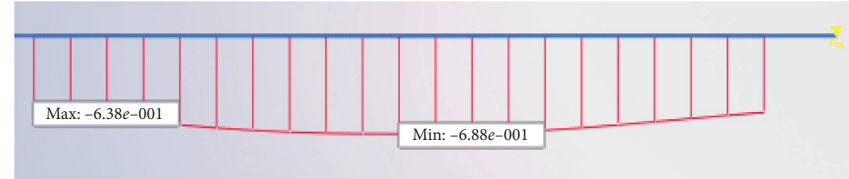

(b)

FIgure 7: Calculation value of displacement of drainage plate: (a) PVDs and (b) PHDs.

squeezed to the reinforced area (horizontal displacement is expressed as negative), while in the process of surcharge preloading, the trend of extrusion of soil from the reinforced area to the affected area (horizontal displacement is expressed as positive) is generated. In the early stage of vacuum preloading, the horizontal displacement in the direction of the reinforcement area increases linearly and rapidly and gradually slows down after reaching the maximum negative value. This is due to the beginning of vacuum pumping; the vacuum degree in the film increases rapidly; and the vacuum suction makes the soil in the influence area move to the reinforced area. Then, with the discharge of pore water, the effective stress of the upper soil increases, and the upper soil exerts pressure on the lower soil, resulting in a gradual decrease in the horizontal displacement. With the increase of surcharge preloading, the soil further slows down the lateral shrinkage deformation of soil under vacuum pressure and gradually produces lateral expansion deformation. The soil moves from the reinforcement area to the influence area.
Figure 10 is the relationship curve between horizontal displacement and depth of soil on the boundary between reinforcement area and influence area with two different drainage structures. From the surface to the bottom of the first layer of soil, the horizontal displacement gradually increases and reaches the maximum value. Then, as the reinforcement depth increases, the horizontal displacement of the soil gradually decreases, indicating that the horizontal displacement of the soil on the soft soil surface is large and is greatly affected by the drainage preloading. The deeper the depth, the less affected. In addition, the abrupt change position of the slope of the relationship curve is the junction between the soil layers, indicating that the horizontal displacement of the soil is greatly affected by the properties of the soil layer.

3.3. Calculation and Analysis of Pore Water Pressure. Figure 11 is the cloud diagram of pore water pressure calculation of vacuum combined surcharge preloading with 


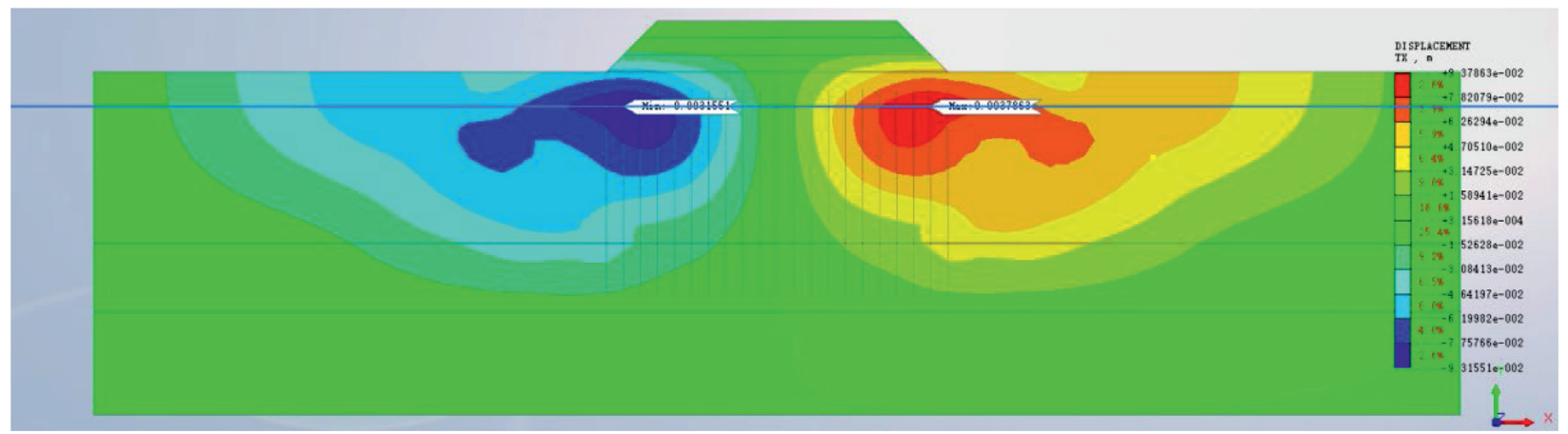

(a)

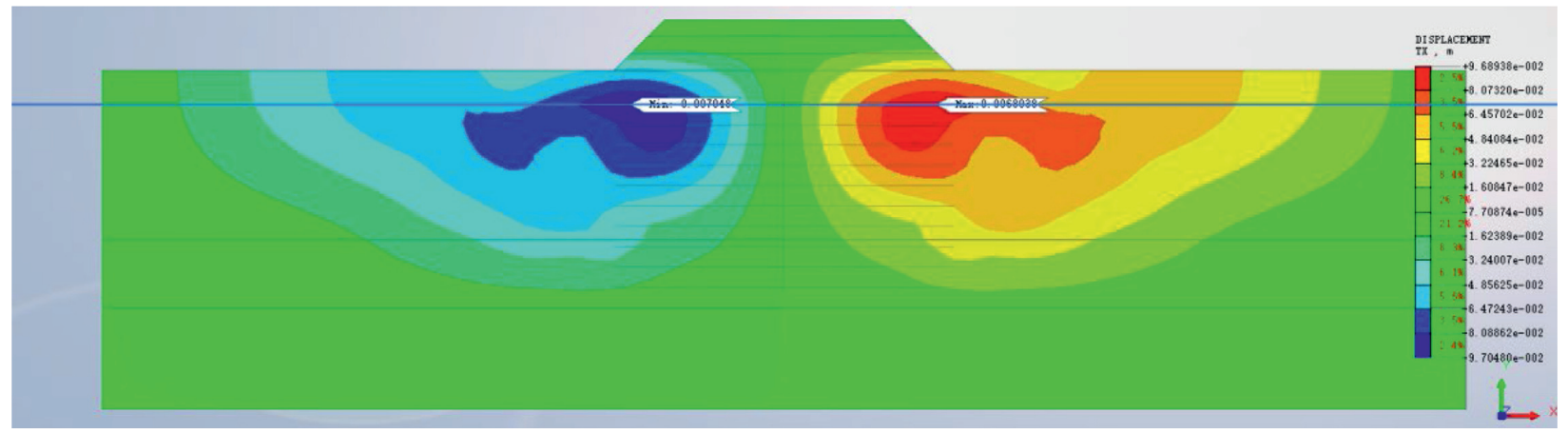

(b)

Figure 8: Cloud chart of horizontal displacement calculation: (a) PVDs and (b) PHDs.

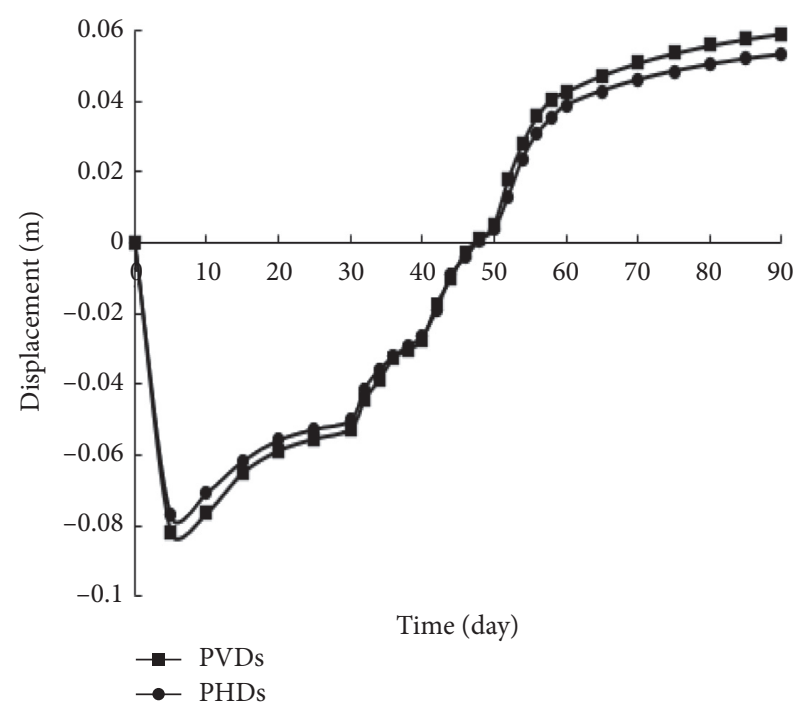

FIGURE 9: Relationship curve between horizontal displacement and time.

two different drainage plates. It can be seen from the diagram that the pore water pressure considering the well resistance effect decreases with the increase of depth in the reinforcement area. The change curve is consistent with the function added when defining the node head. In addition, within the depth range of the drainage board, the pore water pressure is obviously affected by the vacuum load, which also has a certain impact on the pore water pressure below the

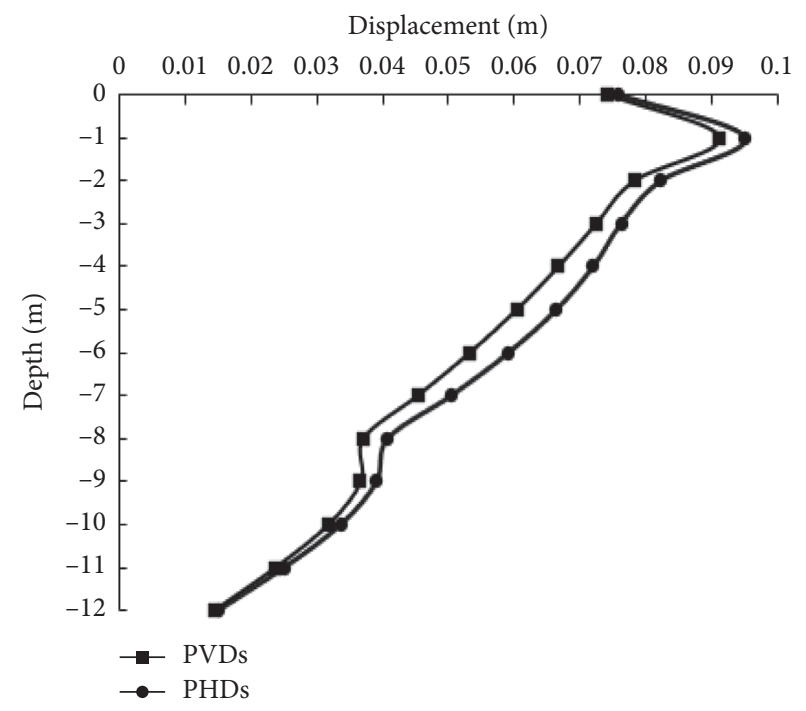

FIgURE 10: Relationship curve between horizontal displacement and depth.

drainage board and in the influence area. The contour line of the pore water pressure of the soil with PHDs is more gentle, indicating that the influence of the PHVs on the pore water pressure of the soil in the affected area is greater than that of the PVDs.

The surface center node of the reinforced area is analyzed, as shown in Figure 12. In the early stage of vacuum preloading, the pore water pressure rapidly dissipates and 


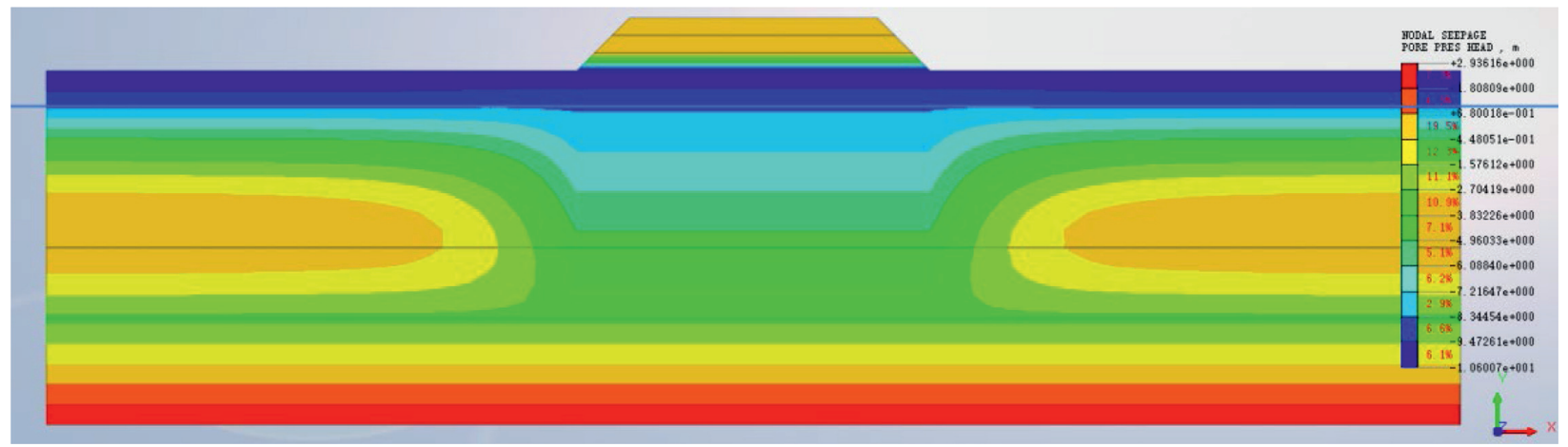

(a)

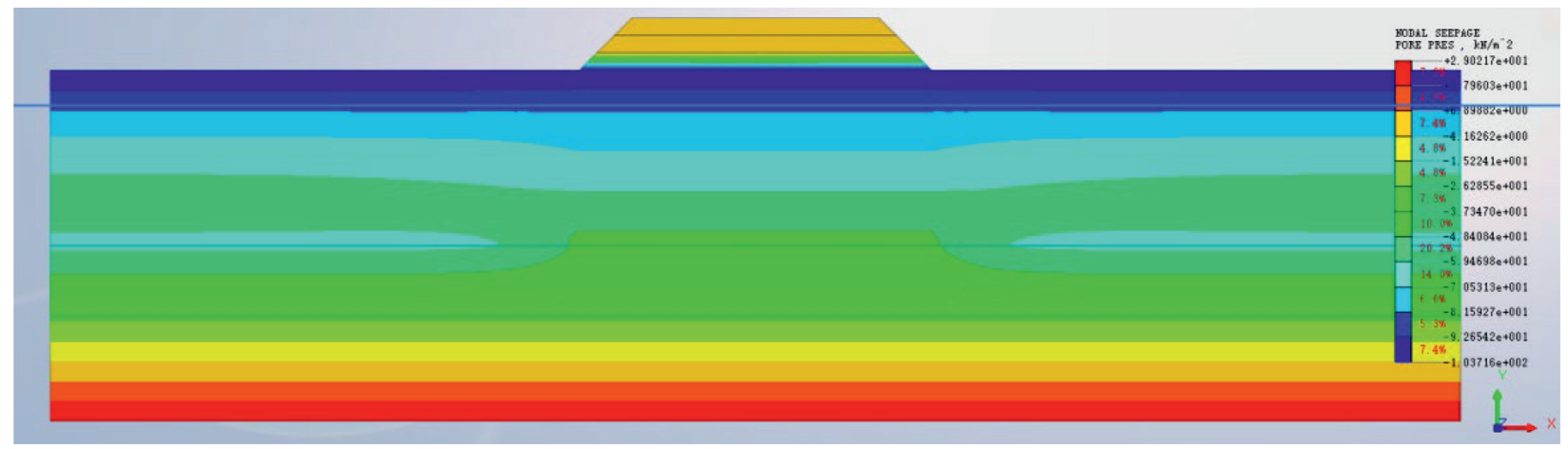

(b)

Figure 11: Calculation cloud chart of pore water pressure: (a) PVDs and (b) PHDs.

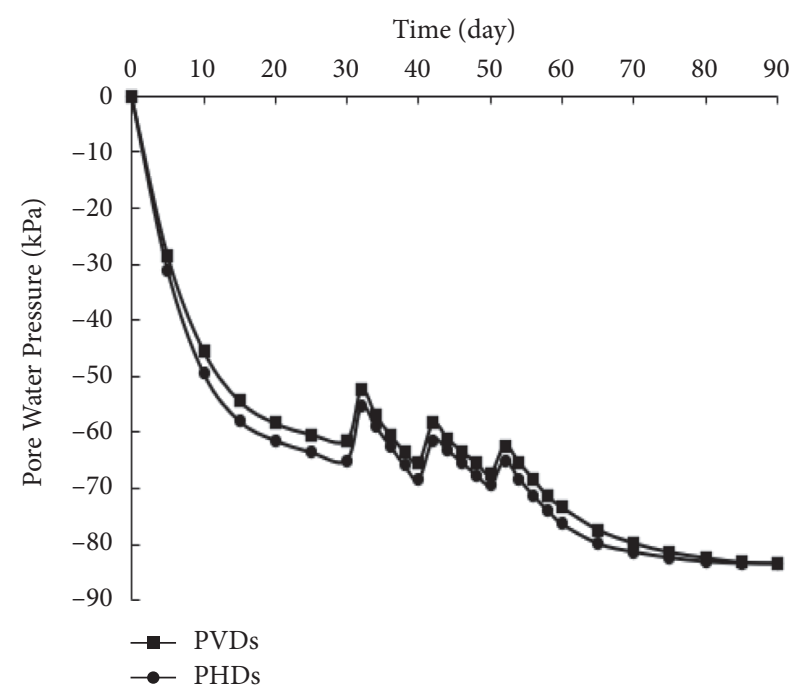

FIGURE 12: Relationship curve between pore water pressure and time.

then gradually slows down under the effect of vacuum negative pressure but still maintains the dissipation trend. Then when surcharge preloading starts, each level of preloading causes the pore pressure to increase suddenly and then dissipate gently. After the surcharge preloading is over, the pore pressure still slowly dissipates until it reaches about $-85 \mathrm{kPa}$ and then tends to be flat. In addition, the diagram shows that the dissipation rate of pore water pressure in the soil layer with PHDs is faster than that with PVDs, and the pore pressure value reaches coincidence in the final stage. This is because the bending deformation of the PHDs is small, and the drainage effect is better. The spacing of the PHDs is gradually reduced in the consolidation process; the drainage path is shortened; and the drainage efficiency is higher, so the pore pressure dissipation is faster. In the final stage, since the vacuum negative pressure set by the node head value of the model is the same, the pore water pressure of the last two is consistent.

\section{Conclusions}

Based on the field test of the first-stage project from Xinhuicheng to Yamen of Guangzhou-Foshan River Expressway, the calculation model of vacuum combined surcharge preloading was established by MIDAS finite element software. The reinforcement effect of the horizontal drainage plate and vertical drainage plate on soft soil such as local silt under vacuum combined surcharge preloading was compared and analyzed, and the following conclusions were obtained:

(1) In the vacuum combined surcharge preloading method, the vertical settlement, horizontal displacement, and pore water pressure with two different drainage plates are analyzed. It is found that the rules of soil consolidation and deformation caused by two kinds of drainage plates are basically 
the same, but in general, the consolidation effect of PHDs is better than that of PVDs.

(2) The maximum vertical settlement of vacuum combined surcharge preloading with PHDs is $742 \mathrm{~mm}$, which are $50 \mathrm{~mm}$ larger than that with PVDs, and the pore water pressure dissipates faster. This is because the spacing of PHDs decreases gradually in the consolidation process, the drainage path is shortened, the drainage efficiency is higher, and the settlement is larger. The maximum horizontal displacement of vacuum combined surcharge preloading with PHDs is larger than that with PVDs, which is $96.8 \mathrm{~mm}$ and $93.8 \mathrm{~mm}$, respectively. The difference between the two is $3 \mathrm{~mm}$, and the difference is not large.

(3) The force and deformation of the two drainage plates are analyzed. It is found that the maximum displacement difference of PHDs is $50 \mathrm{~mm}$, and the maximum displacement difference of PVDs is $80 \mathrm{~mm}$, that is, the deformation of PHDs is smaller than that of the PVDs. This leads to PVDs appearing to one side of the obvious bending; the distance between the drainage plate is farther and farther; drainage path lengthening and consolidation drainage more difficult; and PHDs can move down uniformly with the soil during the consolidation process. The drainage plate has a small bending deformation, which makes the vacuum transfer more uniform and effective.

\section{Data Availability}

The data used to support the findings of this study are available from the corresponding author upon request.

\section{Conflicts of Interest}

The authors declare that they have no conflicts of interest regarding the publication of this paper.

\section{Acknowledgments}

The authors would gratefully like to acknowledge the support provided by the National Natural Science Foundation of China (no. 51978177). The editorial help from Professor Galen Leonhardy of Black Hawk College is also greatly appreciated.

\section{References}

[1] Y. Tang, D. Jiao, and Y. Yang, "Experimental study on strengthening soft foundation by vacuum combined surcharge preloading," Port engineering, vol. 1986, no. 06, pp. 4-15, 1986.

[2] shizuo Shang, "Experimental study on vacuum combined surcharge preloading in a loading and unloading area in shanghai," Port \& Waterway Engineering, vol. 1986, no. 03, pp. 1-08, 1988.

[3] B. Bai, D. Rao, T. Chang, and Z. Guo, "A nonlinear attachment-detachment model with adsorption hysteresis for suspension-colloidal transport in porous media," Journal of Hydrology, vol. 578, p. 124080, 2019.

[4] B. Bai, R. Zhou, G. Cai, W. Hu, and G. Yang, "Coupled thermo-hydro-mechanical mechanism in view of the soil particle rearrangement of granular thermodynamics," Computers and Geotechnics, vol. 137, p. 104272, 2021.

[5] K. Meng, C. Cui, Z. Liang, H. Li, and H. Pei, "A new approach for longitudinal vibration of a large-diameter floating pipe pile in visco-elastic soil considering the three-dimensional wave effects," Computers and Geotechnics, vol. 128, p. 103840, 2020.

[6] C. Cui, K. Meng, C. Xu, Z. Liang, H. Li, and H. Pei, “Analytical solution for longitudinal vibration of a floating pile in saturated porous media based on a fictitious saturated soil pile model," Computers and Geotechnics, vol. 131, p. 103942, 2021.

[7] B. Yuan, Z. Li, Z. Su, Q. Luo, M. Chen, and Z. Zhao, "Sensitivity of multistage fill slope based on finite element model," Advances in Civil Engineering, vol. 2021, pp. 1-13, 2021.

[8] B. Yuan, Z. Li, Z. Zhao, H. Ni, Z. Su, and Z. Li, "Experimental study of displacement field of layered soils surrounding laterally loaded pile based on transparent soil," Journal of Soils and Sediments, vol. 21, no. 9, pp. 3072-3083, 2021.

[9] B. Yuan, Z. Li, Y. Chen et al., "Mechanical and microstructural properties of recycling granite residual soil reinforced with glass fiber and liquid-modified polyvinyl alcohol polymer," Chemosphere, vol. 286, p. 131652, 2022.

[10] L. Yan and J. Yin, "Control of loading rate of vacuum combined surcharge preloading," Highways, vol. 2006, no. 08, pp. 287-290, 2006.

[11] X.-q. Yuan, Q. Wang, W.-x. Lu, W. Zhang, H.-e. Chen, and Y. Zhang, "Indoor simulation test of step vacuum preloading for high-clay content dredger fill," Marine Georesources \& Geotechnology, vol. 36, no. 1, pp. 83-90, 2018.

[12] Y. Lu, J. Chai, and W.-Q. Ding, "Predicting deformation of PVD improved deposit under vacuum and surcharge loads," Geotextiles and Geomembranes, vol. 48, no. 1, pp. 32-40, 2020.

[13] X. Jin, J. Yu, X. Gong, D. Huang, and leixia Yang, "Experimental study on Vacuum Combined Surcharge Preloading reinforcement of soft foundation with confined water," Chinese Journal of Geotechnical Engineering, vol. 2007, no. 05, pp. 789-794, 2007.

[14] X. Li, hang Zhou, H. Liu, and xuanming Ding, "Model test study on consolidation of alluvial fill foundation by air bag pressurization combined with surcharge," Chinese Journal of Rock Mechanics and Engineering, vol. 39, no. S1, pp. 3085-3094, 2020.

[15] H. Lei, P. Wang, L. Xu, and L. Wang, "Analysis of reinforcement mechanism of pressurized vacuum preloading method based on gas migration law," Rock and Soil Mechanics, vol. 42, no. 4, pp. 943-953, 2021.

[16] Y. Wang and J. Wang, "Clogging mechanism of high moisture content dredged sludge drainage plate filter membrane," Port \& Waterway Engineering, vol. 2015, no. 03, pp. 6-11, 2015.

[17] P. Chen, Z. Dong, and G. Zhang, "Formation mechanism and numerical analysis of "soil pile" in shallow surface reinforcement of new hydraulic fill sludge," Port \& Waterway Engineering, vol. 2015, no. 02, pp. 88-94, 2015.

[18] G. Mei, K. Xu, Z. Jinmin, and Z. Yin, "Discussion on deformation mechanism of soft soil foundation strengthened by vacuum preloading," Chinese Journal of Geotechnical Engineering, vol. 28, no. 9, pp. 1168-1172, 2006.

[19] B. Indraratna, C. Bamunawita, and H. Khabbaz, "Numerical modeling of vacuum preloading and field applications," Canadian Geotechnical Journal, vol. 41, no. 6, pp. 1098-1110, 2004. 
[20] J. C. Chai, J. P. Carter, and S. Hayashi, "Ground deformation induced by vacuum consolidation," Journal of Geotechnical and Geoenvironmental Engineering, vol. 131, no. 12, pp. 1552-1561, 2005.

[21] M. Tang and J. Q. Shang, "Vacuum preloading consolidation of Yaoqiang Airport runway," Géotechnique, vol. 50, no. 6, 2000.

[22] J.-C. Chai, J. P. Carter, and S. Hayashi, "Vacuum consolidation and its combination with embankment loading," Canadian Geotechnical Journal, vol. 43, no. 10, pp. 985-996, 2006.

[23] S. L. Lee, G. P. Karunaratne, K. Y. Yong, and V. Ganeshan, "Layered clay-sand scheme of land reclamation," Journal of Geotechnical Engineering, vol. 113, no. 9, pp. 984-995, 1987.

[24] J. Xiusan, H. Shangcai, J. Bingri, and J. Zhengji, "The effects of negative pressure and drain spacing in the horizontal method for an early settlement of dredged and filled grounds," Journal of Korean Society of Coastal and Ocean Engineers, vol. 15, no. $1,2003$.

[25] L. H. Li, Q. Wang, N. X. Wang, and J. P. Wang, "Vacuum dewatering and horizontal drainage blankets: a method for layered soil reclamation," Bulletin of Engineering Geology and the Environment, vol. 68, no. 2, pp. 277-285, 2009.

[26] S. Bao, Z. Dong, H. Mo, and P. Chen, "Field research and development of vacuum consolidation drainage system for recently dredged silt foundation," Chinese Journal of Rock Mechanics and Engineering, vol. 33, no. S2, pp. 4218-4226, 2014.

[27] Pukhov, Y. Pan, and D. Khoteja, "Model experimental study on treatment of high moisture content dredged sludge by flocculation horizontal vacuum two-stage dewatering method," Rock and Soil Mechanics, vol. 41, no. 5, pp. 15021509, 2020.

[28] J. Lin, S. Bao, and B. Zhang, "Analysis on main influencing factors of vacuum preloading reinforcement effect of recently dredged silt foundation," Port \& Waterway Engineering, vol. 2015, no. 12, pp. 138-143, 2015.

[29] W. Zhang, X. Wang, J. Xie, B. Pan, J. Chen, H. Zhao et al., "Experimental study on treatment of hydraulic fill flow mud by vacuum preloading of horizontal drainage plate," Port \& Waterway Engineering, vol. 2016, no. 07, pp. 122-127, 2016.

[30] Y. Zhou, Pukhov, Z. Li, Y. Pan, and D. Song, "Model experimental study on combined treatment of high moisture content dredged sludge with horizontal drain board and vacuum preloading," Chinese Journal of Rock Mechanics and Engineering, vol. 38, no. S1, pp. 3246-3251, 2019.

[31] L. Wang, Q. Chen, S. Liu, and Y. Fu, "Model test of soft clay treated by vacuum preloading combined with electroosmosis of horizontal drainage plate," Chinese Journal of Rock Mechanics and Engineering, vol. 39, no. S2, pp. 3516-3525, 2020.

[32] S. Hansbo, "Consolidation of clay by band-shaped prefabricated drains," International Journal of Rock Mechanics and Mining Science \& Geomechanics Abstracts, vol. 12, no. 5, pp. 16-25, 1979.

[33] W. Zhao, Y. Chen, and Y. Gong, "Treatment method of sand well in plane strain finite element analysi," Journal of $\mathrm{Hy}$ draulic Engineering, vol. 1998, no. 06, pp. 54-58, 1998. 